\title{
Las influencias teológicas judías en el pensamiento de Emmanuel Levinas
}

Jorge Medina*

Resumen: Existe una fuerte influencia teológica sobre el pensamiento fenomenológico de Emmanuel Levinas: la Torah, Caín de Volozhym y Franz Rosenzweig. Las grandes tesis del filósofo lituano están animadas por la concepción judía de la Creación, la Revelación y la Redención, a tal grado, que su humanismo del otro hombre y la reivindicación del Rostro como categoría fundamental de la subjetividad pueden ser comprendidos como un neomesianismo ético.

Palabras clave: Levinas, filosofía judía, alteridad, giro teológico, ética.

Abstract: There is a strong theological influence on the phenomenological thought of Emmanuel Levinas: the Torah, Cain Volozhym and Franz Rosenzweig. The great theses of the Lithuanian philosopher are animated by the Jewish conception of Creation, Revelation and Redemption, to such an extent, that his humanism of the Other and the vindication of the Face as a fundamental category of the subjectivity can be understood as an ethical neomessianism.

Keywords: Levinas, jewish philosophy, otherness, theological turn, ethics.

Résumé: Il existe une forte influence théologique sur la pensée phénoménologique de Emmanuel Levinas: la Torah, Hayyim de Volozhym et Franz Rosenzweig. Les grandes thèses du philosophe lithuanien sont influencées par la conception juive de la Création, la Révélation et le Rédemption, à tel point que son humanisme de l'autre homme et la revendication du Visage comme catégorie fondamentale de la subjectivité peuvent être compris tel un néomessianisme éthique.

Mots-clés: Levinas, philosophie juive, altérité, tournant théologique, éthique.

* Profesor de la Facultad de Filosofía y Ciencias Sociales de la Universidad Panamericana, México. (jmdelgad@up.edu.mx). 


\section{Introducción}

Uno de los aspectos más interesantes que llama la atención es que Levinas no fue un filósofo que renunciase a su religión a la hora de hacer filosofía. Fue judío siempre, un filósofo judío, o mejor dicho, un judío que hizo filosofía desde su historia, su tradición y su fe. No es raro encontrar en sus escritos que a una cita de un filósofo anteceda o prosiga otra de Isaías, Jeremías o del Talmud. Sería injusto, pues, calificar las obras de Levinas en dos categorías: escritos filosóficos y escritos judíos, pues hay tanto judaísmo en los primeros, como filosofía en los segundos: su obra es unitaria. No obstante esta anotación, nuestro pensador dedicó explícitamente cuatro libros a comentarios a pasajes del Talmud: Cuatro lecturas talmúdicas (1968), De lo sagrado a lo santo. Cinco nuevas lecturas talmúdicas (1977), Más allá del versículo. Lecturas y discursos talmúdicos (1982) y Nuevas lecturas talmúdicas (1996); y un libro sobre el judaísmo: Difícil Libertad (1962).

En todos estos libros, y en el resto de su obra, Levinas da testimonio de lo que, a mi parecer, es la más fuerte influencia inspiradora de las categorías que estructuran su propuesta filosófica: el judaísmo. No considero que la influencia literaria, ni la filosófica en su vertiente fenomenológica o en su vertiente dialógica, sean un parangón de lo que representó para el filósofo lituano la lectura atenta de la Torah o del Talmud ${ }^{1}$. Aún más: si las otras influencias sirvieron a Levinas fue en tanto le auxiliaron a sistematizar, profundizar o explicitar las intuiciones bíblicas, las cuales no consideró nunca un objeto de estudio, sino su propia substancia ${ }^{2}$.

1 Su lectura fue influenciada profundamente por las enseñanzas de Chouchani. Al respecto, cfr. S. Wygoda, "Le maître et son disciple: Chouchani et Levinas", en Cahiers d'études Levinassiennes, 1 (2002), pp. 149-183.

2 Cfr. F. Poirié, Emmanuel Levinas. Essai et entretiens, Paris, Babel, 2006, p. 86.
Siguiendo la propuesta del gran historiador del judaísmo y la cábala, Gershom Scho$\mathrm{lem}^{3}$, existen cuatro conceptos básicos en el judaísmo: Dios, Creación/Autolimitación, Revelación/Tradición y Salvación. El primero enuncia la originalidad del monoteísmo; el segundo, la creación ex nihilo y la separación entre el Creador y la creatura; el tercero, el que la verdad sea dada por Dios y recibida y profundizada por la comunidad humana; y el cuarto, la redención de la condición humana por el Mesías. Estos cuatro conceptos dan testimonio del exitus-reditus según la concepción judía: del Dios que es, que crea al hombre, que se comunica con él y que lo lleva a Él. El nuevo pensamiento, inaugurado por Franz Rosenzweig, intenta una nueva concepción de los cuatro grandes conceptos del judaísmo, en un diálogo fecundo con la filosofía occidental. Levinas, influenciado fuertemente por Rosenzweig, tratará también estos temas, pero no de una manera sistemática como su maestro, y tampoco sólo a través de la interpretación de su maestro, sino incorporando la tradición talmúdica lituana, sobre todo del Gaón de Vilna y de Hayyim de Volozhym.

Uniendo, pues, la propuesta de Scholem a quienes teológicamente influenciaron sobre Levinas, en el apartado uno se tratará el concepto de Dios teniendo como fuentes la Torah y el Talmud; el dos expondrá las ideas de creación y contracción de Dios bajo la influencia decisiva del Gaón de Vilna y de los escritos de Volozhym; el tres tratará sobre la idea de Revelación que Levinas expone bajo la influencia de Rosenzweig; y en el último apartado consideraremos las implicaciones de la ética levinasiana entendida como un posible neomesianismo, es decir, en clave de Salvación. Torah-Ética será el nuevo exitus-reditus en Levinas.

3 Cfr. G. Scholem, Conceptos básicos del judaísmo. Dios, creación, revelación, tradición, salvación, traducción de J. L. Barbero, Madrid, Trotta, 2000². 


\section{Torah y Talmud: A la escucha del Otro}

Afirmar que la Torah y el Talmud son el exitus de la propuesta levinasiana no es de ninguna manera afirmar a Dios como el a priori sobre el cual construye un sistema, como el Espíritu que antecede a todo movimiento y que da razón, en su Ser, de todo ser. La Torah (הרות, ley, enseñanza) es el Decir de Dios revelado a Moisés en el Sinaí, es Palabra que comunica y relaciona, Ley que ordena y encauza, Enseñanza que lleva a plenitud. Pero es Dios quien ha tenido la iniciativa: se revela. No es la escarpada caverna que con dificultad sube el filósofo la que da pie al desvelamiento del Misterio; al contrario, el judaísmo, en su fuente principal, la Ley, y su correlato de tradición oral cristalizada en el Talmud, es una excepción de la primitiva religiosidad humana: es Dios, en un principio, quien viene al hombre, no éste quien va a Él.

Levinas no duda en afirmar que la definición misma de hombre es la comunidad entre él y Dios, y que la finalidad de toda educación es esa sociedad 4 . Pero puesto que, por una parte, el ser humano es libre y, por otra, Dios tiene la iniciativa, él ha dado el medio para que la sociedad Dios-hombre se consume: la Torah. Las leyes de la Torah no se deben reducir a una coerción sobre la libertad del fiel, al contrario, son el orden que Dios participa al hombre para que éste alcance el rango de lo auténticamente humano ${ }^{5}$. Ser destinatario de la Ley es ya ser elegido, ser partícipe de la responsabilidad por el otro. La Ley, pues, desde esta perspectiva, lleva a plenitud el designio divino del hagamos al hombre a nuestra imagen y semejanza.

Es así como Levinas afirma que "lo que el judaísmo aporta al mundo, no es la simple generosidad del corazón, ni visiones metafísi-

4 Cfr. E. Levinas, Difficile liberté. Essais sur le judaïsme (En adelante DL), Paris, Le livre de poche, 1984, p. 27. [Edición castellana: Difícil Libertad. Ensayos sobre el judaísmo (En adelante $\mathrm{DL}^{*}$ ), introducción y traducción de M. Mauer, Buenos Aires, Lilmod, 2004.

5 Cfr. E. Levinas, Nouvelles lectures talmudiques (En adelante NLT), Paris, Les éditions de Minuit, 1996, p. 84. cas inéditas, sino un modo de existencia guiada por la práctica de los mitsvot (mandamientos)" ${ }^{\prime \prime}$. Pero los mandamientos deben ser vividos y encarnados en el tiempo y en el espacio, en el seno de una comunidad de hombres que también tienen como meta ser una sociedad. La sociedad humana, pues, es el modo de vivir los mandatos que, cumplidos, conducen a la sociedad con Dios. La vida comunitaria de la Ley, el comentario vital que hicieron los rabinos de la Ley, y que se recoge en la tradición, es el Talmud ${ }^{7}$ (דומלתה, Doctrina). Sería inviable para el judaísmo, y en especial para Levinas, que la sola lectura de la Biblia constituyera la fuente única de la Revelación, pues también lo es la Tradición. Ley-sociedad-Dios son lo subyacente al Talmud, o como lo afirma nuestro pensador, "la relación a la ley es la relación a otro hombre [...] en esto estriba todo el pensamiento talmúdico"s.

El judaísmo, de la Torah y del Talmud, busca educar al hombre para que se instituya una relación entre el hombre y la santidad de Dios y para que esta relación se mantenga. No obstante, la relación que pretende no es de absorción, no es entusiasmo ( $\dot{v} v \theta o v \sigma \iota \alpha \sigma \mu o ́ s$, es decir, endiosamiento ${ }^{9}$ ), sino relación en el seno de la alteridad. En efecto, para Levinas, "lo numínico o lo sagrado envuelve y transporta al hombre más allá de sus poderes o de sus voluntades. Pero esos excesos incontrolables resultan ofensivos para una verdadera libertad [ ] No porque la libertad sea una finalidad en sí misma, sino porque sigue siendo la condición de todo valor que el hombre pueda alcanzar. Lo sagrado que me envuelve y me transporta es violencia"10. Nuestro autor está conciente también de que esta ruptura con lo sagrado, tal como lo conciben los paganismos, antiguos o modernos,

6 E. Levinas, Quatre lectures talmudiques (En adelante QLT), Paris, Les éditions de Minuit, 1968, p. 180.

7 Una buena introducción a la noción y división del Talmud, la hace Levinas en QLT, pp. 10-11.

8 M. Saint-Cheron, Entretiens avec Emmanuel Levinas, Paris, Le livre de poche, 2006, p. 45.

9 Alusiones a esta elevación humana que, tras el éxtasis, despoja al ser humano de su propio ser para confundirse con Dios, las encontramos, por ejemplo, en el Ion de Platón (535b y 536d).

10 DL*, p. 95 
comporta el riesgo del ateísmo ${ }^{11}$, pero, precisamente en ello, ve la trascendencia que implica la fe: "Es una gran gloria para el Creador haber creado un ser que lo afirma después de haber dudado de él y de haberlo negado en los prestigios del mito y del entusiasmo; es una gran gloria para Dios la de haber creado un ser capaz de buscarlo o de escucharlo desde lejos, a partir de la separación, a partir del ateísmo"12.

Enlacemos pues, los conceptos anteriores: el judaísmo, como religión del Libro (Torah leída desde la tradición talmúdica), busca la sociedad Dios-hombre, pero no por vía extática o numinosa -y de ello da prueba el constante recelo que Levinas tiene durante sus obras de la Cábala como camino religioso--. ¿Cómo, pues, busca colmar el anhelo siempre humano de la trascendencia con su Creador? El judaísmo es novedoso en su respuesta: "sintiendo la presencia de Dios a través de la relación con el hombre. La relación ética aparecerá en el judaísmo como relación excepcional: en ella, el contacto con un ser exterior, en lugar de comprometer la soberanía humana, la instituye y la inviste"13. El Talmud -tanto en su Halakha (הלכה, conducta) que contiene todos los preceptos rituales, sociales, éticos o económicos, como en su Haggadah (הגדה, dicho, relato) que contiene las exégesis u homilías no legales- da cuenta de que los mandamientos refieren al prójimo como el en donde de la relación con Dios. Incluso aquellos mandamientos que pudieran parecer rituales y relativos a la esfera individual ${ }^{14}$, están enmarcados en un calendario, precisamente porque es en la historia de la comunidad donde cada fiel encuentra a Dios.

En otras palabras, la Torah y el Talmud, como escucha atenta a Dios, "Otro por excelen-

11 Sobre la constitución a-tea del hombre, es decir, creatura separada de Dios, de un Dios siempre trascendente, se tratará en el numeral siguiente.

$12 \mathrm{DL}^{*}$, p. 96.

13 DL ${ }^{*}$, p. 97.

14 Véase el comentario al tratado Yoma (85a-85b) que hace Levinas a propósito del Yom Kippur, en donde afirma que un pecado contra Dios no es perdonado en el judaísmo -aún contando con la eterna disposición de Dios a perdonar- sino en un día determinado, para que así, en reunión -mediación- con la comunidad, se evite toda tentación a una religiosidad intimista. (Cfr. QLT, pp. 35-39). cia, Otro absolutamente otro, Otro en tanto que otro"15, son la verdad ética, y el profetismo, el modo en que esta verdad se hace patente. Levinas entiende el profetismo como un momento de la misma humanidad -no tanto el don particular de los llamados profetas-, puesto que "asumir la responsabilidad por otro es para todo hombre una manera de testimoniar la gloria del Infinito, de ser inspirado. Hay profetismo, hay inspiración en el hombre que responde por el otro, paradójicamente, antes incluso de saber lo que se exige concretamente de él. Esta responsabilidad ante la Ley es revelación de Dios"16. Levinas está convencido de que la Biblia es el resultado de profecías, de testimonios éticos sociedad hombre-hombre donde se hace presente la sociedad Dios-hombre-; pero no es un conjunto de profecías de cuya lectura se obtiene una moral de lo cotidiano, sino que es profetismo que llama al profetismo, aventura ética que involucra al oyente de la Palabra a aventurarse éticamente en el mundo en que habita.

Los versículos piden ser interpretados ${ }^{17}, \mathrm{y}$ esta interpretación, expresada en la dialéctica del Talmud, tiene como fuente la vida e historia del pueblo. La interpretación no se da, para Levinas, en la inspiración intelectual solitaria que Dios da al hombre para que éste descubra en el texto bíblico la verdad; la inspiración es el momento ético, la relación con el otro donde se manifiesta el Otro. En nuestro autor se trueca la sacralidad del Libro por la santidad del Otro, el acceso inmediato a la divinidad por el mediato: "la voz de Dios es voz humana, inspiración y profecía en el hablar de los hombres"18. La Biblia, al descentrar, en su profetismo, al yo de sí, lo remite en verdad al otro, y en él, al Otro. La Biblia es verdadera trascendencia, alteridad, vera religione.

En síntesis, la escucha del Otro, que no se evade en ritualismos, es ética: "que la relación con lo divino atraviesa la relación con los

15 QLT, p. 36; NLT, p. 83.

16 E. Levinas, Éthique et Infini (En adelante EI), Paris, Le livre de poche, 1984, p. 111.

17 Cfr. NLT, p. 33.

18 NLT, p. 37. 
hombres y coincide con la justicia social, tal es el espíritu de la Biblia judía. Moisés y los profetas no se preocupan por la inmortalidad del alma, sino por el pobre, la viuda, el huérfano y el extranjero" ${ }^{\prime 19}$. Levinas ve que Dios no puede anular la responsabilidad del hombre por el otro hombre; es esta responsabilidad el designio divino: el allí del encuentro con Él. Por eso, respecto a los pecados que comete el hombre contra Dios, Dios persona, pero respecto a los pecados cometidos contra el prójimo, no, porque, como dice Rabbí Yitzhak en su comentario (Yoma, 85a): "cualquiera que aflige a su prójimo, incluso con palabras, debe apaciguarlo para ser perdonado". Esta dura religión -y aquí ya se puede constatar su distanciamiento del cristianismo- que ve Levinas en el judaísmo queda claramente afirmada cuando dice que: "el mal no es un principio místico que se puede borrar por un rito; es una ofensa que el hombre hace al hombre. Nadie, ni siquiera Dios, puede sustituir a la víctima. El mundo donde el perdón es todopoderoso se hace inhumano" ${ }^{20}$.

Sin embargo, aunque el prójimo es el allí de la relación con Dios, Dios mismo no es un Neutro infinito, que se encarna temporalmente en el otro; no, Dios es Alguien, no algo. Dios tiene Nombre. Para el pensamiento hebreo, el Nombre de Dios encierra ya la manera misma de la relación del hombre con Él. Nombrarlo es participar de la relación. Cuando Levinas hace una exégesis del tratado Shebuot (35a) relativo a los Nombres de Dios en la Escritura observa que no existe un nombre genérico para designar a la divinidad, tal como en otras lenguas sería Dios, God, Dieu, Deus... En lengua hebrea no existe ese sustantivo; por el contrario, Dios es designado, en cualquiera de sus nominaciones, con un Nombre propio. De estros Nombres, Levinas llama la atención sobre "el Santo, Bendito sea Él", que atribuye a Dios la Santidad,

$19 \mathrm{DL}^{*}$, p. 100.

20 Ibídem. Hay que advertir, sin embargo, que la alusión que hace Levinas es incorrecta, pues el Evangelio también insiste en la reconciliación directa con el prójimo como antecedente al encuentro con Dios: “Por tanto, si al presentar tu ofrenda en el altar recuerdas que tu hermano tiene algo contra ti, deja allí tu ofrenda delante del altar, y ve primero a reconciliarte con tu hermano; después, vuelve y presenta tu ofrenda" (Mt 5, 23-24); por lo que no se puede hablar de la inhumanidad del perdón infinito en el cristianismo. entendida como la separación (Ab-soluto de Dios). Este Nombre contrasta con otro, Shekinah, que hace referencia a la presencia de Dios en el mundo, en la comunidad. Ambos Nombres no designan la esencia de Dios, sino su relación con nosotros ${ }^{21}$. Dios está presente, pero a la vez, ausente. ¿Cómo su Ser Absoluto puede ser presente en su ausencia? Esta misma pregunta se vuelve a hacer si se considera que el Nombre del Nombres, escrito en el Tetragrámaton y revelado por Dios a Moisés, se puede escribir pero no pronunciar, en su lugar, el judío pronuncia Adonai (mi Señor). El Nombre de Dios, pues, "se muestra y se disimula" 22 , y esto mismo ocurre, incluso, cuando a Dios se le implora en la plegaria, pues al llamarle por su Nombre, se establece la relación con un Tú (segunda persona), pero al estribar el contenido del Nombre en la fórmula de bendición, el Tú se transforma en Él, y así se tiene que el creyente habla a Dios diciéndole "Santo, Bendito sea Él".

La relación con Dios, con su Nombre, no se logra por la rectitud del conocimiento, sino por la obediencia a sus mandatos: proximidad más grande que cualquier proximidad, adherencia integral $^{23}$. Por el contrario, creer que mediante el conocimiento se puede dominar la realidad, incluida la divina, es hechicería y magia. Ésta, la kechafim ${ }^{24}$, es una contestación, negación o controversia con "lo Alto", un sobrepasar los límites de la verdad, y querer ver (conocer) más allá de lo posible ${ }^{25}$, tentación siempre presente, no en los paganos, sino en quienes han recibido la Revelación, y que buscan desacralizar lo sagrado a través de la anulación de la santidad que comporta la separación.

\footnotetext{
21 Cfr. E. Levinas, L'au-delà du verset (En adelante AV), Paris, Les éditions de Minuit, 1982, pp. 147-148.

22 Tratado Kidushin, 71a, apud. AV, p. 150.

23 AV, p. 145

24 Levinas explica que este término proviene de las consonantes de cada palabra de la fórmula "makhichin famalia chel maala" ("Ellos niegan la Asamblea de lo Alto"); en tanto la brujería consiste en negar el orden superior, en prolongar el no luciferino ante el Sí creador de Dios. (Cfr. E. Levinas, Du sacréau saint. Cinq nouvelles lectures talmudiques (En adelante SS), Paris, Les éditions de Minuit, 1977, p. 99).

25 Cfr. SS, p. 96: “La sorcellerie, c'est la curiosité qui se manifeste là où il faut baisser les yeux, l'indiscrétion à l'égard du Divin, l'insensibilité au mystère, la clarté projetée sur ce dont l'approche demande de la pudeur".
} 


\section{El Gaón de Vilna y Volozhym: Creación y contracción}

Levinas nació en Kaunas (Kovno), Lituania ${ }^{26}$, hacia 1906, fecha en que el territorio formaba parte de Rusia. Con los lituanos, el judaísmo conoció su desenvolvimiento intelectual más profundo, allí se dio propiamente la ilustración judía del siglo XVIII. En cierta medida el aliciente de dicho florecimiento fue una pugna intestina entre dos corrientes judías: los hassidish y los mitnagdim; a la cabeza de éstos se encontraba el célebre Gaón ${ }^{27}$ de Vilna, Rabbí Elijah ben Schlomo ${ }^{28}$, y a la cabeza de aquéllos, el famoso Baal Schem Tov $^{29}$. El hassidismo pretendía restaurar la esperanza y alegría de un pueblo en sufrimiento a través de un misticismo popular, mientras que los mitnagdim (opositores), veían en la Torah la participación de la vida divina y en su estudio, la tarea contemplativa más excelsa. La pugna se exacerbó con las excomuniones lanzadas por el Gaón sobre el movimiento hassídico tanto en Lituania como en Polonia. A su discípulo, Rabbí Caín de Volozhym, le tocó la enorme tarea de reivindicar los estudios talmúdicos y de atraer a los hassidish evitando más cismas. Sin dificultad se puede apreciar que el distanciamiento entre hassidismo y talmudismo no desapareció, y que incluso en el siglo XX hubo dos expositores magistrales de sendas corrientes: Martin Buber y Emmanuel Levinas, respectivamente.

A sabiendas de que el legado del Gaón y de Volozhym es grande y que sus incursiones en el

26 Cfr. Poirié, Emmanuel Levinas..., ob. cit., p. 63: “Beaucoup de synagogues, beaucoup de lieux d'étude. La ville neuve était vraiment plus neuve. Quand on prononce le mot Lituanie, on ne sait peut-être pas qu'il désigne une des parties de cette Europe orientale où le judaïsme connut son développement spirituel le plus haut: le niveau de l'étude talmudique était très élevé, et il y avait toute une vie basée sur cette étude et vécue comme étude".

27 Este título se utilizó después del siglo VII para designar a la cabeza de las academias talmúdicas babilónicas, y literalmente significa "sabio". Estas academias dieron paso a las yeshivot, institutos de estudio de la Torah y del Talmud, de las cuales la primera fue fundada por el mayor discípulo del Gaón de Vilna: Caín de Volozhym.

28 Se puede profundizar más sobre su figura en: I. Etkes I., Gaon of Vilna: The Man and His Image, traducción al inglés de J. M. Green, Berkeley, University of California Press, 2002; G. D. Hundert, Jews in PolandLithuania in the Eighteenth Century: A Genealogy of Modernity, Berkeley, University of California Press, 2004.

29 Cfr. H. Klépfisz, Baal Schem Tov, Buenos Aires, Congreso Judío Mundial, 1967, pp. 5-25.
Talmud al igual que en la Cábala son muy amplias, centraremos la atención en dos aspectos que, a nuestro parecer, son los que más influyeron en el pensamiento levinasiano: la creación y la contracción. Ambos temas son tratados en el libro póstumo de Volozhym El alma de la vida (Nefesh haHayyim), sobre todo en su sección inicial: "el primer pórtico". Levinas da cuenta de su influencia tanto en el prólogo que él hace a la traducción francesa de dicha obra, como en el artículo "A la imagen de Dios", compendiado en Más allá del versículo (1982); sin embargo, al parecer de importantes $\operatorname{críticos}^{30}$, la influencia de Volozhym está presente en las principales tesis de Levinas a lo largo de su obra.

Volozhym, como se mencionó anteriormente, intenta reconciliar el estudio de la Torah como valor supremo de la vida religiosa con la comunión con Dios (דבקות, devequt) predicada por los hassidish. La clave para tal reconciliación está en la noción de "mandamiento" (מצווה, mitsva), pues en él, cada persona constata la Presencia de Dios y permite que dicha Presencia se irradie al resto de la creación. Pero, ¿qué significa la creación misma de Dios y qué función cumple el ser humano dentro del universo creado al obedecer los mandamientos divinos?

Narra el Génesis $(1,27)$, que “Dios creó al hombre a su imagen, a imagen de Elohim lo creó". Volozhym ve que en esta frase está encerrado el gran misterio del hombre. El hombre es imagen (בצלם, tselem) de Elohim -y no de otro atributo o Nombre divino-, el cual designa a Dios como "Amo del conjunto de fuerzas", pues Él creó todo de la nada, llamó y llama continuadamente al ser a todo, de ahí que sea la Fuerza del resto de fuerzas que operan en el universo. No obstante esta diferencia entre Dios y el resto de los seres, Él ha querido confiar al hombre "el poder de desarrollar o de restringir los millares de miríadas de fuerzas y de mundos"31, haciendo así del hombre su vicario.

30 Cfr. C. Chalier, La huella del infinito. Emmanuel Levinas y la fuente hebrea, traducción de M. Pons Irazazábal, Barcelona, Herder, 2004; C. Mopsik, "La pensée d'Emmanuel Levinas et la Cabale", en Cahier de l'Herne. Emmanuel Levinas, Paris, Éditions de l'Herne, 1991, pp. 442-460.

31 C. Volozhym, L'âme de la vie, prefacio de E. Levinas, traducción al francés de B. Groos, Paris, Verdier, 1986, p. 95. 
Atando algunos postulados de la Zohar respecto a las diez sefirot o emanaciones divinas con el estatuto humano como tselem de Elohim, Volozhym desgaja dos conclusiones fundamentales: que cada mundo ${ }^{32}$, encadenado como está con los demás, depende de su mundo superior para poder desarrollarse -si el hombre está por debajo del Trono de Dios, entonces del hombre mismo depende la conexión del universo con Dios y de Dios con el universo-; y que el hombre, creado al final de los seis días, resume en sí todos los mundos, es un microcosmos ${ }^{33}$.

El hombre, entonces, no sólo tiene la grave responsabilidad de relacionarse con su Creador, sino también de relacionar a Él todo lo creado: es amo de las fuerzas en tanto responsable de las fuerzas. De su actuar depende nada más y nada menos que continúe con eficacia la creación de Dios: Dios depende del hombre ${ }^{34}$, ya que "cuando el hombre actúa siguiendo la voluntad de su Creador y cumple uno de sus mandamientos, por la fuerza que anima uno de sus órganos, actúa al mismo tiempo sobre la fuerza del mundo superior correspondiente a este órgano. El la restaura, la eleva, da una intensidad suplementaria a su santa luz, conforme al deseo y la voluntad del Muy-Alto, Bendito sea Él. Según el valor y la intensión de su acto, según la pureza y la santidad de su pensamiento al momento del cumplimiento -intensión que se añade a la materialidad del acto-, le confiere un máximo de eficacia" ${ }^{35}$.

32 Para comprender más la noción de "mundos", Cfr. Ibídem, p. 102: "On sait que tous les mondes se recouperent et se répartissent suivant quatre divisions: ofanim (les roues de la Merkaba), hayot (les saintes bêtes, êtres vivants qui entourent le Trône), le Trône céleste, l'Émanation de sa Sainteté, béni soit-Il. L'âme de chacun de ces mondes est le monde situé au-dessus de lui, selon la description du prophète Ezéchiel I, 21".

33 Volozhym interpreta el plural "hagamos al hombre..." del Génesis, como la convocación que hace Dios para que todas las creaturas ya creadas donen parte de su fuerza y esencia para la formación del ser humano; de esta manera, el hombre posee en sí las fuerzas de todos (aunque recibidas), y así se constituye en verdadera imagen de Elohim, Amo de las fuerzas (de suyo tenidas). Cfr. Ibídem, pp. 107-109.

34 A. Hazan, "La notion du temps dans la pensée hébraïque", en Les études philosophiques, 38/2 (1984), p. 184: "Le temps est un concept qu'interpelle l'homme, continuellement; le sens en reste ouvert, car tout n'a pas été donné à la fois. Le Juif qui en assume la responsabilité est son protagoniste au sens étymologique du terme. Il ne serait pas exagéré d'affirmer que Dieu Lui-même a besoin de l'homme et est, à la limite, convoqué par l'homme pour les célébrations du Temps ouvrant la voie à l'Historicité".

35 Volozhym, L'âme de la vie..., ob. cit., p. 111.
La asociación que desde su creación tiene el hombre a todas las fuerzas del universo, hace que su actuar decida no sólo la marcha de su vida, sino de la vida toda. Así lo ha dispuesto Dios, según el pensamiento de Volozhym, al crear al hombre a imagen suya, es decir, a imagen de Elohim. De ahí que el hombre no sea sólo viviente, como los demás seres creados, sino el alma de lo viviente (Nefesh haHayyim). Mas, ¿cómo creó Dios un ser semejante a sí al grado que pueda impedir o frenar el continuado acto creador de Dios?, ¿este ser creado no da cuenta de que lo creado en cuanto tal es alteridad, diferencia, distancia, hasta el grado de decir "no" al Creador e impedir su obra? Pensar en la creación es pensar en la separación.

Para Volozhym y muchos otros cabalistas, como Caín Vital o Isaac Luria, para que hubiera creación de un ser separado, era necesario que Dios -que llenaba todo el "espacio" metafísi$\mathrm{CO}-$, se contrajera, se retirara dentro de sí para dar cabida a un ser distinto de sí. Que Dios creara en su seno hubiera significado panteísmo, es decir, no-creación; sin embargo, el objetivo de los cabalistas no era insistir en esta separación, sino repararla, encontrar las vías para que se consumara la unión Dios-hombre. Levinas, por su parte, recogerá sólo la tesis inicial ${ }^{36}$ : la separación, y dejará la final: la fusión. Aún más, Levinas da razón a Volozhym en cuanto Elohim creó al hombre a su imagen, pero su ser consiste en la contracción (tsimtsum), en la disimulación y humildad que suponen la alteridad del otro; somos imagen de Dios cuando imitamos el momento contráctil de acto creador, es decir, no cuando creamos en nosotros, sino cuando dejamos ser otro que nuestro ser.

Como hace notar Scholem ${ }^{37}$, el tsimtsum de Dios no pudo haber sido un simple replegarse

36 Cfr. Chalier, La huella del infinito..., pp. 35-36: “esa creación [...] anuncia una temporalidad distinta, una temporalidad separada de las necesidades del momento, ya que está orientada hacia la alteridad de ese Dios retirado de la «extensión ontológica», lo que significa un Dios que ha puesto en el ser una existencia separada de él, una existencia que, sobre todo el día del shabat, se mantiene próxima al más allá del ser $[\ldots]$ Levinas, por su parte, insiste en el carácter positivo de la separación ontológica entre Dios y sus criaturas: 'Lo esencial de la existencia creada consiste en su separación frente a lo Infinito'",

37 Cfr. Scholem, Conceptos básicos del judaísmo..., ob. cit., pp. 71-74. 
de Dios en sí para crear lo distinto a sí al inicio de la creación, sino que implica un continuo y reiterado acto de contracción, una autolimitación constante de su ser para que lo ya creado no quede dentro de Él. Si cesara la contracción, cesaría la alteridad de la creación: quedaría solo Dios. Según la liturgia judía, Dios renueva todos los días la obra inicial de la creación... Dios renueva todos los días su contracción. El hombre, para Levinas, es imagen de Dios en un sentido siempre renovado de autolimitación, de anonadamiento continuado del yo, que asegure, no la emergencia del tú por unos instantes, sino toda la vida. Por tanto, si la noción de creación supone la autolimitación, y ésta posibilita la alteridad, entonces se puede afirmar la existencia de la multiplicidad.

Sin embargo, la contracción no anula la relación. Al respecto cabe señalar la referencia que hace Volozhym a la discrepancia aparente entre unos versículos de la Torah que dan pie a una discusión talmúdica ${ }^{38}$. En ésta, dos querubines, afirma un pasaje de la Escritura, tienen sus rostros viendo hacia las paredes de la casa y dándose la espalda entre ellos; mientras que en otro pasaje afirma que los querubines se ven cara a cara. El discípulo del Gaón ve en esta aparente contradicción la corroboración de sus tesis sobre las relaciones Dios-hombre. Un querubín representa a Dios, y el otro, a su pueblo. Cuando su pueblo desobedece sus mandatos, y voltea el rostro a Dios, mueve con su voluntad los mundos superiores, por lo que éstos también le voltean el rostro. Cuando Israel cumple los mandatos de Dios, Él le ve, cara a cara y, viendo a Israel, ve al universo entero: obra sus prodigios ${ }^{39}$.

Hay pues, posibilidad del encuentro cara a cara a pesar, o mejor dicho, gracias a la separación. El hombre sería imagen más nítida de Elohim si viera a su prójimo cara a cara,

38 Talmud, Tratado BabaBatra, 99a.

39 Cfr. Volozhym, L'âme ..., p. 125: “De même, Dieu dit: 'Je t'assimile et te compare, ô mon amie...' Bien que je chevauche Arabot, c'est toi, pour ainsi dire, qui par tes actes, me dirige. Car mon association aux mondes dépend exclusivement de la direction que tu imprimes à tes actes. L'Écriture dit en effet: 'Il chevauche les cieux, par ton aide...' (Deutéronome 33, 26)". cuando cumpliendo los mandatos de Dios, e imitando la autolimitación divina, dejara ser al otro. La posibilidad del encuentro cara a cara es actuar conforme a las exigencias de la Torah. No cumplirlas, es voltear el rostro a Dios e impedir que Él siga creando: ¡la ética posibilita o imposibilita la ontología!, o como afirma Levinas en el prefacio al Nefesh haHayyim: "El ser es a través de la ética del hombre. El reino de Dios depende de mí. Dios no reina más que por la mediación de un orden ético, aquél donde precisamente un ser responde de otro. El mundo es, no porque persevere en su ser, no porque ser sería su propia razón de ser, sino porque, por la mediación de lo humano, puede ser justificado en su ser. Lo humano es, antes de toda determinación antropológica, la posibilidad misma de un ser-para-el-otro" ${ }^{40}$.

En lo anterior estriba el drama de la existencia humana que a su vez vuelve dramáticos la existencia del mundo y el actuar de Dios. Cumplir los mitsvot supone para el hombre perfeccionar y terminar de acabar lo inacabado de su creación ${ }^{41}$, siendo así co-creador de sí junto con Dios; cumplir los mitsvot supone también cooperar como imagen de Elohim en la construcción del mundo. La imitación de la autolimitación divina se verifica, para el creyente, en el cumplimiento de los mandatos, pues estos suponen una contención y límite, abstinencia y prohibición. No obstante, la prohibición, al limitar la espontaneidad vital -movimiento centrípeto del ego- instaura la auténtica humanidad, posibilita la civilidad ${ }^{42}$. De esto se desprende que los grandes pecados sean castigados con la expulsión o exclusión (kareth) de la comunidad. Esto da pie a considerar la prioridad de la ética y su carácter fundacional: Aristóteles a la inversa, pues no es la ética una parte de la po-

40 Ibídem, p. 12

41 Cfr. NLT, p. 84: "Mais, dans l'axiologie de la Thora, la mitsva, le commandement divin de la Loi, ne se réduit pas à une emprise oppressive exercée sur la liberté du fidèle. Il signifie, jusque dans son poids de contrainte, tout ce que l'ordre du Dieu unique apporte déjà de participation à son règne, de divines proximité et élection et d'accession au rang de l'authentiquement humain. Comme si le 'faisons un homme' de Genène 1, 26 laissait et laisse encore de l'inachevé. Dans l'apparente sub-ordination de l'obéir à Dieu, la liberté du quant-à-soi reste toujours à prendre".

42 Cfr. NLT, pp. 23-25. 
lítica ${ }^{43}$, sino lo contrario. Política, economía, lógica, ontología... todas ellas derivan de la ética y presuponen, en su conjunto, la existencia de la alteridad frente al in-finito (Ein-Sof), al modo como una mariposa ronda en torno al fuego sin jamás consumirse o integrarse en él ${ }^{44}$. Y aceptar la alteridad es aceptar la carga de la responsabilidad que supone que todo un Dios no obrará sin mí, que su justicia no devendrá sin mí.

\section{Franz Rosenzweig: El nuevo pensamiento ante la Revelación}

La guerra es un motor poderoso de la reflexión humana. Levinas y Rosenzweig comparten este acicate; pues mientras que a éste la Primera Guerra, la Gran Guerra, le motivó a poner en duda la pertinencia y vigencia de la noción moderna de civilización, a aquél, la Segunda Guerra Mundial le hizo cuestionarse la noción misma de humanidad. El siglo XX -sus guerras- puso en duda los ideales ilustrados de libertad, fraternidad, igualdad y progreso; verificó el dicho heraclídeo de la paternidad y reinado de la guerra.

La Estrella de la Redención (1921), la gran obra de Franz Rosenzweig, se presenta como una respuesta, o si se prefiere, como una nueva pregunta, ante la guerra, ante la muerte. En la introducción a la Estrella, el filósofo de Kessel anticipa ya la fuerte crítica al idealismo y al materialismo, al observar en ellos tentativas de acallar la presencia de la muerte y disolver la angustia que produce, con el pensamiento de la Totalidad. En palabras de Rosenzweig, "un Todo no ha de morir, y en el Todo nada moriría. Sólo lo aislado puede morir, y todo lo mortal está solo. Que la filosofía tenga que suprimir del mundo lo singular y aislado, este des-hacerse del Algo y des-crearlo, es la razón de que la filosofía haya de ser idealista. Pues el idealismo, con su negación de cuanto separa a lo aislado del Todo, es la herramienta con la que la filo-

43 Ética Magna, I, 1 (1181a25-30).

44 Cfr. E. Levinas, De Dios que viene a la idea (En adelante DVI*), traducción de G. González R. Arnaiz y J. M. Ayuso Díez, Madrid, Caparrós, 2001, p. 132. sofía trabaja la rebelde materia hasta que ya no opone resistencia a dejarse envolver en la niebla del concepto del Uno-Todo" ${ }^{45}$. Y sin embargo, cada muerte que ocurre, cada hombre que muere, es una nueva muerte, un algo que ocurre; el aguijón de la muerte vuelve a verter su veneno en el idealismo ciego y soberbio que contempla impávido al otro que muere.

Pero para ocultar la muerte, el idealismo la ha llamado nada. El ser identificado con el pensar lo es Todo, la muerte del singular, Nada. Reducción y negación son los pilares sobre los que se erige la filosofía idealista: todos y cada uno de los singulares no son más que momentos de un Todo único y cerrado, en donde su individualidad es negada para no desgajar la Totalidad. De Tales a Hegel, según Levinas ${ }^{46}$, se confirma la aseveración anterior, pues la búsqueda de un único elemento fundante de la realidad equivale a presuponer la realidad como un Todo unificado o unificable: el agua, el aire, la Historia, el Estado... implican que la particularidad adquiere sentido hasta que se subsume en una realidad superior que la hace inteligible. Por el contrario, aceptar la separación y la creación, sería aceptar la exterioridad en el Sistema, el más allá del Todo; y así, la verdad que provenga de fuera del sistema sería revelación. He aquí que alteridad y revelación son convertibles: Rosenzweig a la base de Levinas ${ }^{47}$.

La Estrella es muy sistemática en su propuesta. En su primera parte trata de los elementos irreductibles de la realidad: Dios, hombre y mundo; en esa parte se esbozan las críticas al idealismo que tiende a reducir a una única realidad tales elementos. El hecho de que Dios no se reduzca al mundo le da un carácter Metafísico; el que el mundo no se reduzca al sentido que de él guarde la mente humana que unifica la pluralidad en la unidad a través del logos, lo hace metalógico; el que el hombre no se reduzca a una

\footnotetext{
45 F. Rosenzweig, La eEstrella de la Redención, edición preparada por M. García-Baró, Salamanca, Sígueme, 1997, p. 44

46 Cfr. DL*, p. 195

47 Levinas comenta en Totalidad e infinito que La Estrella de la Redención le ha impresionado tanto, sobre todo en su oposición a la idea de totalidad, que dicha obra está demasiado presente en su libro como para ser citada.
} 
naturaleza común, fija y estática, a un ethos que lo determinaría y unificaría a todos los hombres en torno a una misma esencia, hace de él un ser metaético ${ }^{48}$. Como introducción a la primera parte se pregunta sobre la posibilidad de conocerlo todo, o bien, de conocer el Todo; como conclusión, ve retrospectivamente los elementos en el caos inicial, y como perspectiva, la posible unión que conservase su irreductibilidad, es decir, la relación o comunión.

La segunda parte trata de los elementos en su relación. Es interesante notar cómo Rosenzweig acude a la estrella de David para ejemplificar los dos aspectos de su análisis: elemental (cap. I) y relacional (cap. II): En el primer triángulo, las aristas señalan los elementos irreductibles: Dios, hombre y mundo; en el segundo triángulo, ya superpuesto al primero, las aristas señalan la relación que guardan las aristas del primer triángulo que flanquean dicho punto. La vida misma - la vida cotidiana, como afirma Rosenzweig al final de la Estrella- es la relación: en la vida, Dios, el hombre y el mundo se encuentran. La vida no vincula ni formal ni abstractamente a dichos seres, sino que la vida es la expresión concreta y fehaciente de dicho encuentro: Dios y el mundo, por la Creación; Dios y el hombre, por la Revelación; el hombre (marcado por la Revelación) y el mundo (marcado por la Creación), por la Redención. Mas la relación, por ser concreta, engendra el tiempo. La Creación da luz al pasado y lo establece como horizonte, pues lo creado, como participio, entraña siempre el tiempo pretérito. La Revelación, como amor a la singularidad humana es mandamiento de amor, amor siempre renovado y renovante que impulsa en su ahora a amar perpetuamente, engendra el tiempo presente ${ }^{49}$. Por último, el amor de Dios que se revela orde-

48 Cfr. E. Levinas, Fuera del sujeto (En adelante HS*), traducción de R. Ranz Torrejón y C. Jarillot Rodal, Madrid, Caparrós, 2002, pp. 69-70.

49 Cfr. HS*, p. 71: "El judaísmo, en el que la revelación no se separa del mandamiento, no significaría por lo tanto el yugo de la Ley, sustituido por la caridad, de acuerdo con un nuevo mensaje de la revelación. La Ley es el mismo acoso del amor. El judaísmo, tejido de mandamientos, atestigua la renovación de los instantes del amor de Dios por el hombre, sin la que el amor ordenado no habría podido ser ordenado. La mitsvá -el mandamiento que mantiene en suspenso al judío- no es un formalismo moral, sino la presencia viva del amor, la "temporalización" misma del presente como se dice hoy en día: experiencia original del presente y de la presencia". na al hombre un movimiento hacia su prójimo, pero "amar al prójimo es ir a la Eternidad, redimir el Mundo o preparar el Reino de Dios. El amor humano es el trabajo mismo, la eficacia de la Redención. Así la Revelación comienza la Redención que abre la dimensión del amor humano, obra de un ser absolutamente singular o mortal que participa en la Eternidad" 50 .

En la tercera parte de La Estrella, Rosenzweig trata tanto el judaísmo como el cristianismo, no como un apartado propio de la filosofía de la religión, sino como figuras eternas de la redención. El fuego, la vida en Dios, es la figura del judaísmo, mientras que los rayos, difusión de la vida de Dios, son la figura de un cristianismo peregrino y misionero ${ }^{51}$. Al final de la tercera parte y de todo el libro se encuentra la verdad, el hexágono que queda al interior de los triángulos superpuestos. La verdad es la facticidad misma de los elementos y su relación, es el " $y$ " de "Dios y el mundo y el hombre", es la verificación de la relación en medio de la pluralidad. Además, la verificación que propone Rosenzweig en su "nuevo pensamiento" es gradual, pues partiendo de las verdades evidentes se llega a aquellas cuya verificación supone comprometer la vida entera: el testimonio.

En palabras del mismo Rosenzweig, es una “teoría del conocimiento mesiánica, que valora las verdades según el precio de su veri-ficación [...]. Sólo en Dios mismo se encuentra consumada la verificación, sólo ante Él es la verdad una. La verdad terrena permanece, pues, escindida -dividida en dos como la facticidad extradivina, como los hechos originarios mundo y hombre. En estos hechos finales que son el judaísmo y el cristianismo, ellos retornan con su y como mundo de la ley y fe del hombre, como ley del mundo, y hombre de la fe" ${ }^{\prime 2}$. La conclusión del tercer capítulo, y del libro entero es el retorno a la vida cotidiana; es un pasar (puerta) del libro a

\footnotetext{
50 HS $^{*}$, p. 72.

51 Cfr. T. Chanter, "Levinas and impossible possibility: Thinking ethics with Rosenzweig and Heidegger in the wake of the Shoah" en Research in Phenomenology, 28/1 (1998), pp. 96-97.

52 F. Rosenzweig, El nuevo pensamiento, edición de A. Garrido-Maturano y F. Lebenglik, Buenos Aires, Adriana Hidalgo Editora, 2005, p. 48.
} 
lo que es más allá del libro, como si para vivir la cotidianidad (Alltag) en tanto día del todo (Alltag) hubiese sido necesario recorrer de punta a punta la vida de los elementos y relaciones del todo (Lebenstag des All) ${ }^{53}$.

En expresión del mismo Rosenzweig y de sus críticos, la parte medular y fundamental de La Estrella es el tratamiento de la Revelación (II, 2). En efecto, el vuelco que se opera ad intra del concepto de subjetividad estriba en la noción de Revelación. El ser humano, en su momento elemental, no es más que un sí mismo cerrado, autosuficiente; sólo en la medida en que es interpelado por otro ser humano, deja de ser un mero sí mismo para transformarse en un yo. Aunque el yo parecía ser tópico central de los filósofos modernos, no lo fue en el aspecto dialógico; Rosenzweig observa un salto indebido del sí mismo al yo, mientras que sólo se es lo segundo en tanto le precede un Tú que interpela al sí mismo, lo hace salir de sí, y lo refiere a una realidad distinta, nueva, ignota.

La dinámica de la Revelación descubre la pluralidad de sujetos. Dios se comienza a revelar cuando pregunta a Adán “¿Dónde estás?”. En esta pregunta lo interpela, lo llama "tú", mostrándose realmente como un "Yo" divino. No obstante, ante esa pregunta "el hombre se oculta; no responde; permanece mudo; sigue siendo el Sí mismo que conocemos. A la pregunta divina por el Tú no contesta un Yo, un yo soy, un yo lo he hecho. A la boca que responde acude, en vez de yo, un él, ella, ello" ${ }^{54}$. Es necesario que el Yo humano sea pura disposición, apertura, oído a la voz divina que lo llama, tal como lo hizo Samuel al responder a Dios: "Habla, porque tu servidor escucha” (1 S 3, 10).

Pero, ¿en dónde se condensan tanto la interpelación del yo como la disposición o acogida del tú? En el mandamiento. En efecto, para Rosenzweig, en tanto tiempo presente -no memoria ni advenimiento-, el mandamiento presupone a un yo que se dirige a un tú. Sin

53 Cfr. Ibídem, p. 49.

54 Rosenzweig, La Estrella de la Redención..., ob. cit., p. 221. embargo, ¿acaso no puede el tú frente al mandamiento volver a cerrarse en el yo adánico que es Sí mismo, irresponsable (sin respuesta)? Sí, el yo puede permanecer Sí mismo, excepto que se trate del mandamiento de los mandamientos: Amarás al Eterno, tu Dios, como todo el corazón y toda el alma y con todas tus fuerzas. El primer mandamiento ordena amar, y en esto estriba que no se pierda su permanente carácter dialógico, ya que el amor sólo es susceptible de mandarse si viene de boca del amante, éste es el único capaz de decir "ámame", y sólo es lícito mandarlo porque previamente ha escuchado el amante del amado su confesión de amor, la aceptación de su amor.

El amor se comprende, pues, como tiempo presente "exigencia de amor a partir de la aceptación del amor"; inicialmente parte de Dios, pero cuando el hombre comprende que el presente amoroso es también mandato y exigencia "pues el amor manda amar", vuelve hacia lo otro que sí para amarlo, torna al mundo, en especial, al prójimo ${ }^{55}$. La vuelta al mundo y su consideración como destino de amor funda el tercer tipo de relación de las substancias separadas: la Redención.

Por ésta, según Rosenzweig, el hombre aproxima a la Creación a su Creador en acto de amor, responde al amor de Dios amando él mismo lo que Dios ha amado -y por tanto constituido en Tú- que es su mismo prójimo, a quien el hombre también está mandado a llamar Tú. Por tanto, la Creación, como acto de amor, no es aún formalmente diálogo, porque lo creado no es capaz de responder a Dios; en la Revelación, Dios llama Tú al hombre, habilitándolo (llamándolo y mandándolo) a que él también a su vez lo llame Tú; pero sólo es en la respuesta efectiva, en el amor concreto y presente con

55 Cfr. S. Mosès, Más allá de la guerra. Tres estudios sobre Levinas, traducción de D. Barreto González y H. Sánchez, Barcelona Riopiedras, 2005, pp. 30-31: “En verdad la subordinación del Yo en relación a Dios $\mathrm{y}$ al prójimo son dos aspectos de una misma estructura de experiencia [...] Esta asimetría fundamental en la relación Yo-Tú, donde el Tú precede siempre al Yo, se traduce, desde el punto de vista de la ética, en la subordinación del sujeto al mandato. En efecto, el mandato -independientemente de su contenido específico- significa una ruptura de la autonomía humana, sumisión a un absolutamente otro que inviste la subjetividad desde afuera". 
que el hombre responde a otro hombre como finalmente el diálogo se consuma, y este es el momento redentor ${ }^{56}$.

Revelación es, por tanto, resquebrajamiento de la autonomía. Es el otro quien manda, quien es ley constituyente de mi propio $\operatorname{ser}^{57}$. Revelación es comunión en el seno de la separación y, por tanto, en el de la libertad. Esta idea influye en Levinas para quien Dios se revela al que libremente puede responder o no a su amor y en esto estriba la novedad del judaísmo frente al paganismo: Dios no posee, ama; no hay posesión divina, sino responsabilidad ante Dios ${ }^{58}$.

$Y$, sin embargo... el acto de amor hacia el prójimo también se vuelve un imperativo de amor, una renovación presente del mandamiento original y originario. El mandato de amor tal como lo proponía Rosenzweig es ahora incorporado por Levinas en destacando su vertiente prescriptiva: La otra cara de la Redención es la profecía, es decir, el acto por el cual Dios habla a través del yo a un tú prolongando su amormandato. Por eso en boca del profeta Dios dice Yo..., porque sólo un Yo en primera persona es capaz de amar y, por tanto, mandar el amor; por eso en el profeta Dios dice a su pueblo: ámame. La Revelación es, vista desde esta perspectiva, el ahora $^{59}$ siempre nuevo y renovado del Dios que dice por boca del profeta "te amo" y que exige también por boca del profeta "ámame". Ser

56 Es interesante notar cómo también en esta tesis de Rosenzweig hay una cercanía grande con el Nefesh haHayyim de Volozhym; pues si en éste el acto ético humano posibilitaba la acción creadora de Dios, impidiéndola o permitiéndola, en aquél la Redención se opera en el actuar ético humano y, por tanto, Dios está en suspenso del hombre -de cada hombre- para redimir al Universo entero. En Volozhym el Universo no es creado sin el hombre; en Rosenzweig, el Universo no será redimido sin el hombre. Levinas bebe de ambas fuentes sin duda alguna, y es tan acentuada esta carga o peso ontológico, que la vida moral se vive casi en exclusividad como una culpabilidad. El mero estar del yo ahí, en el mundo, y su conciencia de responsable de la creación y redención de los demás y de lo demás, hace decir a Levinas con Pascal que se ocupa un lugar bajo el sol en calidad de usurpación (culpabilidad); lugar que bien pudo haber tomado otro y responder mejor que yo a Dios.

57 Cfr. M. Mack, "Franz Rosenzweig's and Emmanuel Levinas's Critique of German Idealism's Pseudotheology" en Journal of Religion, 83/1 (2003), p. 58.

58 Cfr. DL, p. 91: “L'enthousiasme est, après tout, la possession par un dieu. Les juifs ne veulent pas être des possédés, mais des responsables. Leur Dieu est le maître de la justice, il juge au grand jour de la pensée et du discours".

59 Cfr. E. Levinas, À l'heure des nations (En adelante AHN), Paris, Les éditions de minuit, 1988, p. 177. profeta es descubrir al otro el amor de Dios, y así, mostrarle el acceso al diálogo a través del diálogo mismo; en la profecía reside la humanización, de ahí que afirme Levinas: "el profetismo es, en efecto, el modo fundamental de la revelación [...] pienso el profetismo como un momento de la misma condición humana. Asumir la responsabilidad por otro es para todo hombre una manera de testimoniar la gloria del Infinito, y de ser inspirado [...]. Hay un texto del profeta Amós que dice 'Dios ha hablado: ¿quién no profetizará?', de ahí que la profecía sea puesta como el hecho fundamental de la humanidad del hombre" 60 .

La anterior intuición dará pie a lo que Levinas llamará la inspiración: el Otro en el Mismo, irrupción de lo Infinito en un continente finito. Aunque aludirá Levinas como precedente de esta tesis a Descartes -la idea de perfección en el cogito-, es sin embargo la presencia del profetismo en el interior del pueblo hebreo lo que el filósofo lituano quiere explicar y presentar a Occidente como modelo de racionalidad, y en este sentido el precedente no son las Meditaciones, sino La Estrella: la voz de Dios es voz humana ${ }^{61} \mathrm{y}$, en tanto amorosa (Rosenzweig) o responsable (Levinas), la voz humana es voz de Dios. Así, el Otro en el Mismo es, para Levinas $^{62}$, sufrimiento que revela la verdad del Otro: su alteridad irreductible, rostro que interpela al yo a la responsabilidad.

El rostro, para Levinas, no es susceptible de subsumirse bajo algún género: todo él es inenglobable. Lo mismo sucede en la búsqueda gramatical de Rosenzweig: la Revelación entra en el momento en que se entabla la relación YoTú, en donde ninguno de los dos es un... - en espera del substantivo que lo integrará a una especie determinada-, sino que es, sin más. "Yo", y no "el yo"; “Tú" y no "el tú", es lo que importa para el filósofo de Kessel, pues la relación-revelación se da entre nombres propios, sin artículo definido o indefinido que los inte-

60 EI, 111-112.

61 Cfr. NLT, pp. 36-37.

62 Cfr. B. Bergo, "Is There a 'Correlation' between Rosenzweig and Levinas?” en The Jewish Quarterly Review, 96/3 (2006), pp. 407-408. 
gre. El nombre propio designa desde ahora lo que para los medievales el individuo angélico: él llena su propio género.

Resulta, pues, que Revelación es diálogo, en tanto por el diálogo, y no por el conocimiento de esencias puras, se llega al nombre propio; en este sentido, el diálogo es el ubi del encuentro con el rostro ajeno ${ }^{63}$. Rosenzweig opera lo que en sus palabras significa el tránsito del pensamiento pensante al pensamiento hablante (Sprachdenken), y éste, en tiempo presente. En sintonía con los tres momentos del segundo capítulo de La Estrella se puede comprender el pensamiento hablante como narración o relato (Creación), como diálogo (Revelación) y como coro (Redención $)^{64}$, pero es en el diálogo donde se recrea el relato de la Creación y se anticipa el coro triunfal de la Redención.

No obstante las similitudes se encuentra una diferencia, a mi parecer la más radical, entre la gramática de Rosenzweig ${ }^{65}$ y la ética levinasiana, y que estriba en que el primero concibe la Revelación como un momento constitutivamente amoroso, en el cual el fundamento de la relación es el "eres mía" que dice el amante cuando la amada responde a su amor con el "soy tuya" 66, mientras que para Levinas el Otro se revela en su infinitud jamás asible aunque siempre próxima: responsabilidad. No será la de Levinas una ética del amor en sentido estricto, sino de la justicia.

63 Al respecto es interesante notar, como lo hace Anckaert, que el evento lingüístico de la Revelación descubre al hombre su verdadero Yo. Se sabe creado a posteriori, hasta que en el encuentro se le revela su propio yo en tanto tú de un diálogo; y se sabe éticamente responsable -redentor-en la medida en que en su diálogo llama tú e integra en el amor a otro yo. Cfr. L. Anckaert, A critique of infinity. Rosenzweig and Levinas, Leuven, Peeters, 2006, pp. 16-17.

64 Cfr. M. Leconte, "Amor al prójimo y responsabilidad por el Otro", en Rosenzweig, El nuevo pensamiento..., ob. cit., pp. 63-65.

65 Para ampliar la confrontación entre la gramática de Rosenzweig del Yo-Tú, con la de otros autores, como Rosenstock, Cohen, Austin o Buber, Cfr. R. Gibbs, Correlations in Rosenzweig and Levinas, Princeton, Princeton University Press, 1994, p. 63 y ss. Por ejemplo, Rosenstock correlaciona las personas, tiempos y modos gramaticales de la siguiente manera, que es más similar a la propuesta levinasiana del sujeto-responsable (yo) y el Otro-mandamiento (tú):

Persona Modo Tiempo Cualidad

Segunda (Tú) Imperativo Presente Dirigido

Primera (Yo) Subjuntivo Futuro Responsable

Tercera (Él) Indicativo Pasado Incontestable

66 Cfr. Rosenzweig, La Estrella de la Redención..., ob. cit., pp. 232-233.

\section{La ética levinasiana frente a la idea del Mesías}

Continuando con el hilo conductor de este trabajo que da cuenta de las influencias teológicas del judaísmo sobre Levinas hemos de concluir con la idea de Mesías que tiene el filósofo lituano, en el entendido que dicha idea coincide con el cuarto concepto básico del judaísmo según Scholem: la Redención. Así como los tres conceptos básicos anteriormente descritos han sido relacionados con una influencia -el de Dios con la lectura de la Torah y el Talmud; el de Creación, con la lectura de los mitnagdim lituanos del siglo XVIII; la Revelación, con Franz Rosenzweig-, este cuarto concepto se habrá de relacionar con una más próxima en el tiempo para Levinas: la shoa, el exterminio de millones de judíos durante la Segunda Guerra Mundial, pues sólo a partir de ese contexto se puede comprender la propuesta ética de Levinas como un sentido para el pueblo judío, como una esperanza en medio del dolor y la muerte.

En un artículo que escribió en 1935 para la revista Paix et droit declaraba que lo que hacía único al antisemitismo hitleriano frente a cualquiera otro de la historia era la patética fatalidad que significaba ser judío ${ }^{67}$. El holocausto no fue para el pueblo judío, según Levinas, una prueba histórica más, una invasión más... fue un momento decisivo: el pueblo judío estaba arrojado allí, pero no en la existencia, sino frente a otro hombre. La noción de ser en Hegel o en Heidegger se encarnaba en esos momentos en el Estado Nazi, de ahí que ya no quedara más refugio en la filosofía germana, había que acudir a la comprensión que ofrecía la Biblia de tal acontecimiento. Así escribía Levinas: “Entre los millones de seres humanos que encontraron allí la miseria y la muerte, los judíos hicieron la experiencia única de un desamparo [déréliction] total. Conocieron una condición inferior a la de las cosas, una experiencia de la pasividad total, una experiencia de la Pasión. El capítulo 53 de Isaías agotó ahí para ellos todo su sentido"68.

67 Cfr. Apud. Institut d'études levinassiennes, “Biographie d'Emmanuel Lévinas", www.levinas.fr/levinas/

68 DL $^{*}$, p. 92 
Los judíos fueron vistos como judíos, no como hombres ${ }^{69}$.

El varón de dolores que profetiza Isaías se encarna en todo el pueblo judío que padecía el holocausto. De ahí que Levinas reconozca el carácter reparador y sustitutivo de dicho pueblo frente a toda la humanidad. La particularidad del judaísmo -su misión de ser el que "ofrece su vida en sacrificio de reparación" - le da su estatuto de universalidad en medio de las naciones, pues "justificará a muchos" al cargar "sobre sí las faltas de ellos". El pueblo judío, en aquel momento, tenía una vocación mesiánica.

Sin embargo, Levinas reconoce que no se ha dicho nada del Mesías si el imaginario colectivo lo considera como alguien que pone milagrosamente fin a la violencia del mundo, al imponer la justicia o al terminar con las contradicciones ${ }^{70}$. Por el contrario, él trata de rastrear dentro de la Tradición lo que pudiera significar el Mesías y de qué manera dicho significado daba cuenta de la vocación histórica del pueblo.

Levinas ve en el comentario al tratado talmúdico Sanedrín 99a, en una alusión que hace Rabí Yochanan en torno a la diferencia entre el mundo futuro y los tiempos mesiánicos, una nota clave: el mundo de armonía y perfección es propio de los justos sin flaquezas, mientras que a los arrepentidos les están reservados los tiempos mesiánicos. Ahora bien, contrastando esta opinión con la de Rabí Samuel, quien niega una relación entre méritos humanos y venida del Mesías ${ }^{71}$, y con la de Rabí Abhou quien afirma que en el lugar donde se encuentran los arrepentidos, los justos no pueden estar, Levi-

69 Al respecto, Levinas narra cómo en el campo de concentración ellos, para los alemanes, eran judíos, no se les reconocía su humanidad; un perro que había por allí, sin embargo, les trataba como hombres, les reconocía una humanidad que los alemanes no. Cfr. Poirié, Emmanuel Levinas..., ob. cit., p. 94.

70 Cfr. DL, p. 95.

71 Por el contrario, Rav, para Levinas, encarna la tesis opuesta, y en cierto sentido se adelanta a la noción de 'fin de la historia' de la Fenomenología del Espíritu, pues "todo depende de las buenas acciones y del arrepentimiento: el advenimiento mesiánico se sitúa a nivel del esfuerzo individual que puede producirse en plena posesión de uno mismo. Ya todo es pensable y ha sido pensado; la humanidad está madura; faltan las buenas acciones y el arrepentimiento" (DL* p. 273); así, el fin de la historia o inicio de la era mesiánica estriba en la eficacia de las buenas acciones. nas termina por fraguar una noción inicial de mesianismo muy peculiar -en sintonía con otro pasaje del Talmud-: el Mesías "está entre los justos que sufren, se encuentra entre los mendigos todos cubiertos de llagas"72. A colación de esto último, el Talmud narra que Rabí Yehoshua ben Levy fue a las puertas de Roma a buscar al Mesías en medio de tales menesterosos y, al encontrarlos, le preguntó a uno: “¿Cuándo será tu llegada?" -dando por hecho que él era el Mesías-, a lo cual el desvalido respondió: "hoy".

El "hoy" de la venida del Mesías recuerda al Salmo 95: "Ojalá escuchen hoy la voz del Señor...". Los tiempos del Mesías no se inauguran, pues, con el solo sufrimiento, es necesaria la cooperación humana, el acto por el cual el hombre se dispone a escuchar la voz del Señor; pero, ¿dicho acto son las buenas acciones, tal como lo pedían algunos talmudistas? Si la respuesta es afirmativa, entonces se hace de la venida del Mesías algo que depende de la acción humana y es, por tanto, un acontecimiento condicionado; si la respuesta es negativa, entonces la venida del Mesías no considera la libertad humana, condición básica de la moralidad y la inmoralidad, motivo mismo de su venida. Este dilema que muestra el Talmud también habita en Levinas y lo acompañará en el resto de sus obras.

Es importante considerar que para Levinas, el capítulo 53 de Isaías no designa sólo a un individuo, sino el modo de existir de muchos individuos. El Mesías "es una vocación personal de los hombres"73; esta vocación personalísima de cada uno se concreta en la responsabilidad ineludible por el otro, y así, tal responsabilidad única (considerada como el principio de individuación para el filósofo lituano) coincide con la vocación única a ser el redentor. De ahí que Levinas afirme: "el Mesías, es el príncipe que gobierna de manera tal que ya no aliena la soberanía de Israel. Él es la interioridad absoluta del gobierno. ¿Existe una interioridad más radical que aquella donde el Yo se ordena a sí mismo? La condición no extranjera por excelencia, es la ipseidad. El

72 DL*, p. 275.

73 DL*, p. 293. 
Mesías, soy Yo; Ser Yo, es ser el Mesías"74. En efecto, de acuerdo a la lógica levinasiana, el Mesías es quien hace suyos los dolores ajenos -siervo doliente de Isaías-, pero soporta los sufrimientos ajenos en tanto "Yo", o si se prefiere, deviene "Yo" en tanto carga el dolor del otro. El paso es claro: no eludir las cargas ajenas es reconocerse responsable; la responsabilidad es principio de individuación, la ipseidad surge por y para los otros, y no como efecto de un ego que se piensa a sí mismo. Así, el mesianismo no es la espera en alguien distinto de mí que cargue con las desgracias -mías y de los demás-, sino que es la situación o momento existencial donde el Yo se sabe y reconoce responsable de todo ante todos.

Ahora bien, el sufriente que el Yo carga sobre sus hombros no es el extraño que viene de lejos, al contrario, es el más próximo, es el otro de aquí y ahora. La era mesiánica no consiste en la paz que es la ausencia de las guerras, sino en la paz con el prójimo; la escatología no es tratada por Levinas como las postrimerías, sino como el juicio que en cada instante se realiza en el encuentro con el prójimo ${ }^{75}$. Pues es el encuentro, desde la perspectiva levinasiana, el momento mesiánico: el momento de la responsabilidad. No en balde Levinas trae a colación los nombres que el Talmud, a partir de algunos textos bíblicos, ha atribuido al Mesías a modo de descripción de características esenciales: Silo (Pacífico), Yinon (Abundancia -fruto de la justicia-), Hanina (Piedad, Amor) y Menajem (Consolador ${ }^{76}$, y enfatiza que este último enuncia la relación cara-a-cara, uno a uno, en cambio, los anteriores suponen relaciones no individuales sino colectivas. Por tanto, el Mesías adviene sólo hasta que es Menajem, es decir, allí donde el encuentro con el prójimo y su sustitución se den cara-a-cara, sin anonimato, sin colectividad que medie ${ }^{77}$.

74 DL*, p. 294.

75 Cfr. R. Bernasconi, “Different styles of eschatology: Derrida's take on Levinas' political messianism", en Research in Phenomenology 28/1 (1998), pp. 5-8.

76 Cfr. DL, pp. 133-136.

77 Cfr. DL, p. 136: “Le tour où la vérité, malgré sa forme impersonnelle, gardera la marque de la personne qui s'est exprimée en elle, où son universalité la préservera de l'anonymat, le Messie viendra. Car cette situation-là est le messianisme lui-même".
Derrida ha visto con claridad que la propuesta mesiánica de Levinas no es en sentido estricto religión, ni teología, sino más bien trascendencia, alteridad: “La escatología mesiánica en la que se inspira Levinas, si no quiere ni asimilarse a lo que se llama una evidencia filosófica, no se desarrolla, sin embargo, en su discurso ni como una teología ni como una mística judías [...] ni como una dogmática, ni como una religión, ni siquiera como una moral [...]. Quiere hacerse entender en un recurso a la experiencia misma. La experiencia misma, y lo que hay de más irreductible en la experiencia: paso y salida hacia lo otro, lo otro mismo en lo que tiene de más irreductiblemente otro: el otro. [...] A decir verdad, la escatología mesiánica no llega a proferirse literalmente jamás: se trata solamente de designar en la experiencia desnuda un espacio, un hueco donde aquélla pueda oírse y donde deba resonar. Este hueco no es una abertura entre otras. Es la abertura misma, la abertura de la abertura, lo que no se deja encerrar en ninguna categoría o totalidad"78.

La visión escatológica se consuma, pues, en la experiencia moral -si es que a lo moral es aplicable el término "experiencia"-, en el sentido en que Dios es accesible sólo a través de la justicia, a través de la substitución única e individual que se realiza entre un Yo que es apelado (e individuado) por el dolor del Otro que llama a su responsabilidad. Yo que debe amar a su prójimo si es que quiere ser Yo: el mandato, heteronomía, funda en último término la autonomía. Levinas, ve, en efecto, que el famoso versículo de la Torah: "Amarás a tu prójimo como a ti mismo" (Lev 19, 18), puede ser leído de distintos modos si la palabra kamokha (רומכ, como tú) no se refiere a "prójimo" sino a lo que lo antecede, quedando la traducción así: "ama a tu prójimo; esta obra es como tú mismo", "ama a tu prójimo; eso eres tú mismo"; "ese amor al prójimo eres tú mismo"79. El mandato, por tanto, da la entidad al Yo, al referirlo al Tú por la responsabilidad y la sustitución.

\footnotetext{
78 J. Derrida, La escritura y la diferencia, traducción de P. Peñalver, Barcelona, Antropos, 1989, p. 113.

79 Cfr. DVI*, p. 128.
} 
En una conferencia pronunciada en París en 1968, durante la Semana de los Intelectuales Católicos, Levinas expuso algunas implicaciones que la noción Dios-Hombre tiene para la filosofía. Recuerda dos ideas fundamentales: el descenso del Creador al nivel de la creatura (pasividad más pasiva de la actividad más activa, es decir, humillación) y la expiación extrema por los demás. Sin embargo, busca aplicar dichas intuiciones religiosas a la ética, y encuentra que son las notas distintivas de la trascendencia, del salir del yo de sí para ir al encuentro con el otro. El coram Deo no se realiza sino en la relación ética: "Entre el Yo y el Él absoluto se inserta un Tú" 80 , aún más: la transubstanciación que implica la idea de un Dios-Hombre para la religión, se analoga con la transubstanciación que implica la substitución ética del Yo por el Otro. Es cierto que ambas transubstanciaciones son "necedad para los gentiles", pero Levinas quiere ir más allá: lo que en un tiempo fue "escándalo para los judíos", a saber, la figura de un Mesías hombre (humilde carpintero) se vuelve a repetir ahora, pero al revés: la idea misma de la sustitución, del mesianismo que subyace a la responsabilidad ${ }^{81}$, de la redención operada desde la ética, ¿no es acaso escándalo para la filosofía y el mundo Occidental?

\section{Bibliografía}

Aristóteles, Complete Works, J. Barnes (ed.), Princeton, Princeton University Press, 1991.

Aguilar López, J. M., Trascendencia y alteridad. Estudio sobre Emmanuel Levinas, Pamplona, EUNSA, 1992.

Anckaert, L., A critique of infinity. Rosenzweig and Levinas, Leuven, Peeters, 2006,

Bergo, B., “Is There a 'Correlation' between Rosenzweig and Levinas?" en The Jewish Quarterly Review, 96/3 (2006), pp. 404-412.

80 Levinas E., Entre nosotros. Ensayo para pensar en otro, Pre-textos, Valencia 2001, 76.

81 Cfr. AV, 12: "L'eschatologie a plusieurs styles et genres et celle qui consiste à se sentir responsable devant l'avenir qu'on espère pour les autres a probablement été découverte par la Bible juive. Elle se trouvait cependant, depuis la création, dans l'humanité de l'homme".
Bernasconi, R., “Different styles of Eschatology: Derrida's take on Levinas' Political Messianism", en Research in Phenomenology 28 (1998), pp. 3-19.

Calin R. y Sebbah F. D., Le vocabulaire de Levinas, Paris, Ellipses, 2002.

Chalier, C., La huella del infinito. Emmanuel Levinas y la fuente hebrea, traducción de M. Pons Irazazábal, Barcelona, Herder, 2004.

Chanter, T., "Levinas and impossible possibility: Thinking ethics with Rosenzweig and Heidegger in the wake of the Shoah" en Research in Phenomenology, 28/1 (1998), pp. 91-109.

Ciocan, C. y Hansel, G., Levinas Concordance, Dordrecht, Springer, 2005.

Derrida, J., La escritura y la diferencia, traducción de P. Peñalver, Barcelona, Antropos, 1989.

Etkes, I., Gaon of Vilna: The Man and His Image, traducción al inglés de J. M. Green, Berkeley, University of California Press, 2002.

Gibbs, R., Correlations in Rosenzweig and Levinas, Princeton, Princeton University Press, 1994.

Hazan, A., "La notion du temps dans la pensée hébraïque", en Les études philosophiques, 38/2 (1984), pp. 183-188.

Hundert, G. D., Jews in Poland-Lithuania in the Eighteenth Century: A Genealogy of Modernity, Berkeley, University of California Press, 2004.

Klépfisz, H., Baal Schem Tov, Buenos Aires, Congreso Judío Mundial, 1967.

Levinas, E., Quatre lectures talmudiques, Paris, Les éditions de Minuit, 1968.

Levinas, E., Du sacré au saint. Cinq nouvelles lectures talmudiques, Paris, Les éditions de Minuit, 1977.

Levinas, E., L'au-delà du verset, Paris, Les éditions de Minuit, 1982. 
Levinas, E., Difficile liberté. Essais sur le judaïsme, Paris, Le livre de poche, 1984. [Edición castellana: Difícil Libertad. Ensayos sobre el judaísmo, introducción y traducción de M. Mauer, Buenos Aires, Lilmod, 2004].

Levinas, E., Éthique et Infini, Paris, Le livre de poche, 1984 .

Levinas, E., À l'heure des nations, Paris, Les éditions de minuit, 1988.

Levinas, E., Autrement qu'être ou au-delà de l'essence, Paris, Le livre de poche, 1990. [Edición castellana: De otro modo que ser o más allá de la esencia, traducción de A. Pintor Ramos, Salamanca, Sígueme, 1995].

Levinas, E., Totalité et infini. Essai sur l'extériorité, Paris, Le livre de poche, 1990. [Edición castellana: Totalidad e infinito. Ensayo sobre la exterioridad, traducción de D. E. Guillot, Salamanca, Sígueme, 1999].

Levinas, E., Nouvelles lectures talmudiques, Paris, Les éditions de Minuit, 1996.

Levinas, E., De Dios que viene a la idea, traducción de G. González R. Arnaiz y J. M. Ayuso Díez, Madrid, Caparrós, 2001.

Levinas, E., Entre nosotros. Ensayos para pensar en otro, traducción de J. L. Pardo, Valencia, Pre-textos, 2001.

Levinas, E., Fuera del sujeto, traducción de R. Ranz Torrejón y C. Jarillot Rodal, Madrid, Caparrós, 2002.

Mack, M., "Franz Rosenzweig's and Emmanuel Levinas's critique of German idealism's pseudotheology", en The Journal of Religion, 83/1 (2003), pp. 56-78.

Mopsik, C., “La pensée d’Emmanuel Levi- nas et la cabale", en Cahier de l'Herne. Emmanuel Levinas, Paris, 1991, pp. 378-386.

Mosès, S., Más allá de la guerra. Tres estudios sobre Levinas, traducción de D. Barreto González y H. Sánchez, Barcelona, Riopiedras, 2005.

Poirié, F., Emmanuel Levinas. Essai et entretiens, Paris, Babel, 2006.

Rosenzweig, F., La Estrella de la Redención, edición preparada por M. García-Baró, Salamanca, Sígueme, 1997.

Rosenzweig, F., El nuevo pensamiento, edición de A. Garrido-Maturano y F. Lebenglik, Buenos Aires, Adriana Hidalgo Editora, 2005.

Saint-Cheron, M., Entretiens avec Emmanuel Levinas, Paris, Le livre de poche, 2006.

Scholem, G., Conceptos básicos del judaísmo. Dios, creación, revelación, tradición, salvación, traducción de J. L. Barbero, Madrid, Trotta, 1998.

Sucasas, A., "Redención y sustitución: el sustrato bíblico de la subjetivación ética en $\mathrm{E}$. Levinas", en Cuadernos Salmantinos de Filosofía, 22/1 (1995), pp. 221-265.

Vazquez Moro, U., El discurso sobre Dios en la obra de E. Levinas, Madrid, Universidad Pontificia de Comillas, 1982.

Volozhym, C., L'âme de la vie, prefacio de E. Levinas, traducción al francés de B. Groos, Paris, Verdier, 1986.

Wygoda, S., "Un midrash philosophique. A propos de la lecture lévinassienne du Talmud", en Cahiers d'études lévinassiennes, 4 (2005), pp. 313-352.

Wygoda, S., "Le maître et son disciple: Chouchani et Levinas", en Cahiers d'études Levinassiennes, 1 (2002), pp. 149-183. 